\title{
A stochastic approach to the operative control of flood flows through a reservoir
}

\author{
Lubomír Jarošl, $^{1,}$, Miloš Starý2, Lucie Březková ${ }^{2}$ \\ ${ }^{1}$ Povodí Odry, State Enterprise, Varenská 3101/49, 70126 Ostrava, Czech Republic. \\ ${ }^{2}$ Brno Technical University, Faculty of Civil Engineering, Institute of Landscape Water Management, Žižkova 17, 602 00, Brno, Czech \\ Republic. E-mail: stary.m@fce.vutbr.cz \\ * Corresponding author. Tel.: +420-596657102. Fax:+420-596612666. E-mail: lubomir.jaros@pod.cz
}

\begin{abstract}
The contribution focuses on the design of a control algorithm aimed at the operative control of runoff water from a reservoir during flood situations. Management is based on the stochastically specified forecast of water inflow into the reservoir. From a mathematical perspective, the solved task presents the control of a dynamic system whose predicted hydrological input (water inflow) is characterised by significant uncertainty. The algorithm uses a combination of simulation model data, in which the position of the bottom outlets is sought via nonlinear optimisation methods, and artificial intelligence methods (adaptation and fuzzy model). The task is written in the technical computing language MATLAB using the Fuzzy Logic Toolbox.
\end{abstract}

Keywords: Operative control of reservoir; Artificial intelligence; Fuzzy inference system; Neural networks; Stochastic forecast; Stochastic control of reservoir; Principle of adaptation.

\section{INTRODUCTION}

Flood protection in catchment areas containing reservoirs is influenced by the retention storage of the functional spaces of the reservoirs, the technical parameters of the output devices (i.e. bottom outlets and emergency spillways), the flow capacity of river beds in the catchment area under the reservoirs, and last but not least, meteorological forecast and its predictive capabilities, together with manipulation of the reservoir bottom outlets in relation to the allowed values of harmless outflows in chosen controlling profiles. Current forecasts of precipitation over such basins (i.e. meteorological models) are used for the control of the reservoirs during the flood episode and are determined based on rainfall-runoff model forecasted flow courses in the controlling profiles of the river bed network. Water inflows into the reservoirs are also simulated, on the basis of which it is possible to carry out appropriate output device handling. The overall objective of the water management system is essential to optimise the management system of the reservoir as a whole. It is clear from this summary that the successful control of a water reservoir or system of reservoirs is dependent on the successful prediction of the distribution of precipitation over the catchment area, both in time and in space, as well as the use of a quality rainfall-runoff model with suitably defined river networks. However, both the forecast precipitation and the simulation of rainfall-runoff processes in the catchment area are loaded with a high degree of uncertainty, which stems from the uncertainty contained mainly in the input quantities entered into the models of the above-mentioned processes, but also in the simplification of the modelled phenomena, in the chosen parameterisation of river beds and inundation, as well as a number of other variables. The forecasting of precipitation and consequently river flow in the catchment area is thus one of the most complex activities in meteorology and hydrology.

This contribution is thematically focused on the issue of reservoir management during flood situations under conditions of uncertainty, which stem from the uncertainties inherent in the measured and forecasted evolution of precipitation in the catchment area above the reservoir.
The issue of water reservoir control is subject to considerable attention worldwide. A variety of case studies has been published in which the decision-making phase of the selected control model involves the use of artificial intelligence methods, including genetic algorithms, fuzzy logic and neural networks, e.g. Chang and Chang (2001), Dubrovin et al. (2002) and Chang et al. (2005). The application of the above methods in the development of control algorithms is also tested during normal operation of the reservoir, with the main criteria being to ensure the necessary volume and quality of water (Butcher, 1971; Chandramouli and Nanduri, 2011; Chaves et al., 2004), especially during flood situations (Chang et al., 2011). These methods can be used in the control models either individually or in combination, depending on the solved problem. A number of Czech authors have examined the application of various artificial intelligence methods in the field of water management, including Nacházel et al. (1999) and Fošumpaur et al. (2002).

\section{METHODOLOGY AND APPLICATION}

Construction of a numerical model of reservoir behaviour was undertaken using the MATLAB development environment (The MathWorks, 1984-2012). A computer model can simulate reservoir behaviour during flood situations and test different methods of controlling outflow water. The model was based mainly on previous works by (Březková and Starý, 2013; Drbal, 1999; Nacházel et al., 2004; Starý, 2001; Starý and Doležal, 2004) and on the assembled regulatory circuit of the dynamic system used in the management entity the PI fuzzy controller. This type of controller has been specifically compiled for use with the Fuzzy Logic Toolbox. Subjective optimisation was employed in order to determine the length of the universe the fuzzy inference system input-output quantities, the type of membership functions of these quantities and their number. For the solution of the ordinary first order differential equation, which describes the flow of water to the reservoir, the Runge-Kutta $4^{\text {th }}$ order numerical method was employed (Starý, 1990). 
The real-life case study selected for the application of the chosen methods was the Vranov reservoir on the Thaya River (river length 174,450 km according to the Morava River Board, the administrative body of the Morava River catchment). The first step was to scale down the retention volume of the reservoir, i.e. the maximum storage level was considered as not including emergency spillways. In the design of the reservoir control algorithm a number of parameters were neglected, including the effect of water loss via evaporation from the free surface of the reservoir, loss via water percolation through the reservoir, the influence of water sampling carried out for water supply purposes (for Vranov, Moravské Budějovice, Dukovany and Znojmo) on the overall balance of surface water, as well as the drainage of water through a small hydropower plant located in the body of the concrete gravity dam. In the numerical solution, the effect of the hydrodynamic flood wave on the storage volume of the reservoir was also not considered.

In the context of the solution the partial output obtained in a previous study was used (Březková and Starý, 2013), which provided the stochastic hydrological forecasting simulated rainfall-runoff model HYDROG (Starý, 1991-2015), based on generated random fields for the spatial distribution of precipitation.

This generator of random rainfall fields was applied to the majority of the Vranov reservoir catchment (Thaya River catchment, Podhradí breech profile) for the significant rainfall episode which occurred from $6^{\text {th }}$ August 01:00 until $17^{\text {th }}$ August 06:00 CET, 2002. Repeated simulations of rainfall-runoff processes, based on the parameterisation of the Vranov reservoir catchment by the HYDROG model (see Fig. 1), were used to create the matrix of forecasted inflow into the reservoir at various decision-making time points of control (repeatedly searching for future manipulation of the bottom outlets), the so-called "fans" of stochastic hydrological prediction. The stochastic distribution of precipitation over the catchment was realised on the basis of real deterministic forecasts of precipitation obtained via the ALADIN numerical weather prediction model, as well as the uncertainty of these predictions. The resulting hydrological predictions were multiplied by a coefficient of 1.1 , reflecting the influence of the existence of a generator of random rainfall fields for approximately $80 \%$ of the Vranov reservoir catchment (see Fig. 1).

The principle of the adopted controlling algorithm is based on an adaptive approach devised in Starý (1991-2015). The solved flood period was divided into a sequence of time shifted decision-making points with the time step $\Delta \tau$ (time controlling correction, see Fig. 2), at which the time controlling correction of runoff water from the reservoir was carried out (change in controlling runoff). At each point of $\mathrm{T}$ and for each of the inflow waveforms (from the matrix of hydrological forecasts of inflow to the reservoir with lengths $\tau$ ), numerical optimisation was employed to determine the waveform of the controlling runoff water from the reservoir (the controlling quantity $w(t)$ ), at the same calculating the resulting controlled discharge from the reservoir $O(H(V(t)), u(t))$, where $H$ is the height of the water level in the reservoir, $V$ is the volume of water in the reservoir, $u$ the percentage opening of the bottom outlets and $t$ is time.

From the described procedure it follows that the number of inflow hydrographs into the reservoir corresponds to the number of controlled discharge waveforms of water from the reservoir. From the matrix of these controlled discharge waveforms and on the basis of the chosen selection criteria, that was selected which matched the chosen probability of exceeding the controlled discharge of water from the reservoir at time $T+\Delta \tau$.

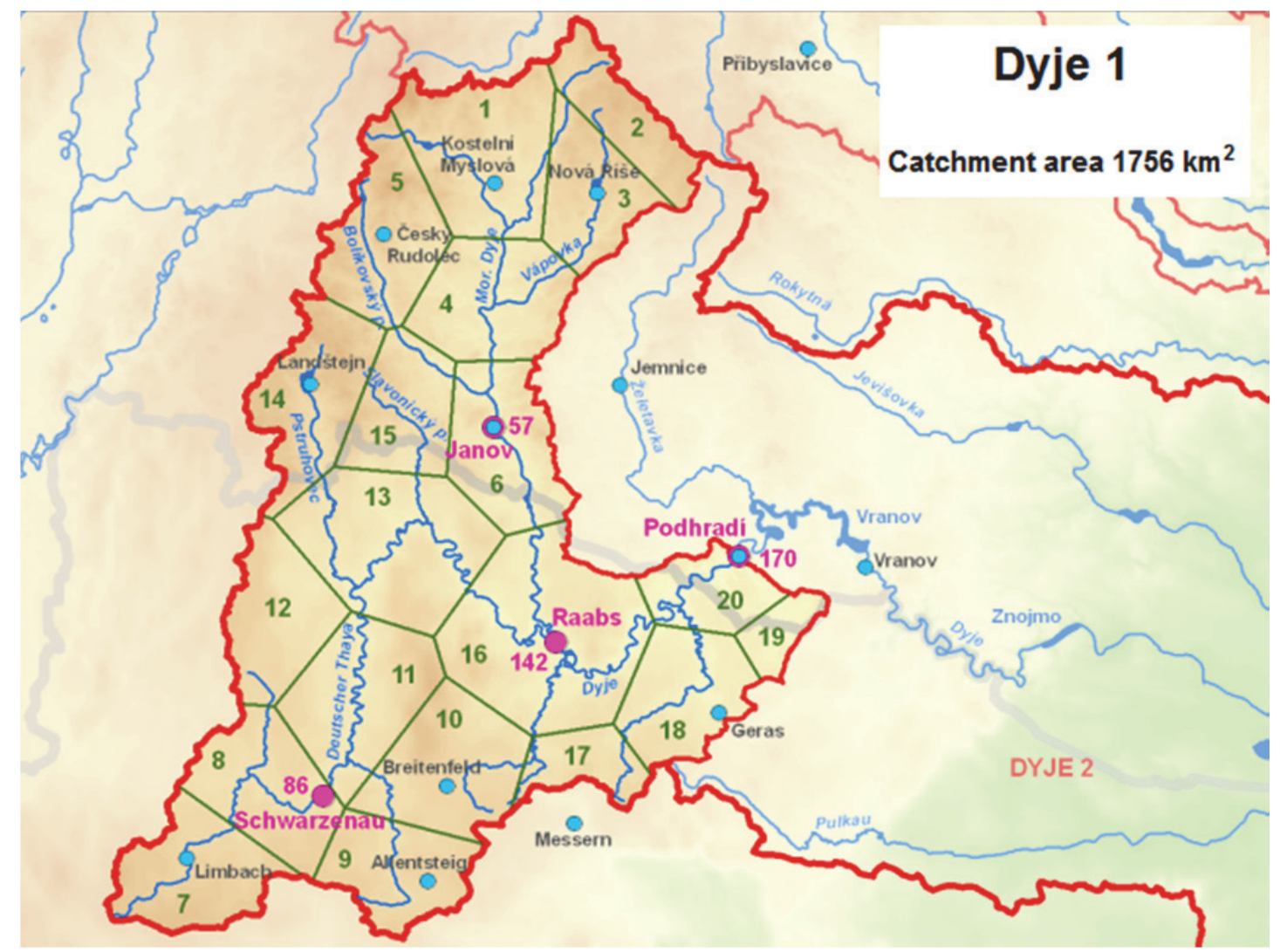

Fig. 1. Parameterisation of the Vranov reservoir catchment by the HYDROG model (source: Czech Hydrometeorological Institute). 


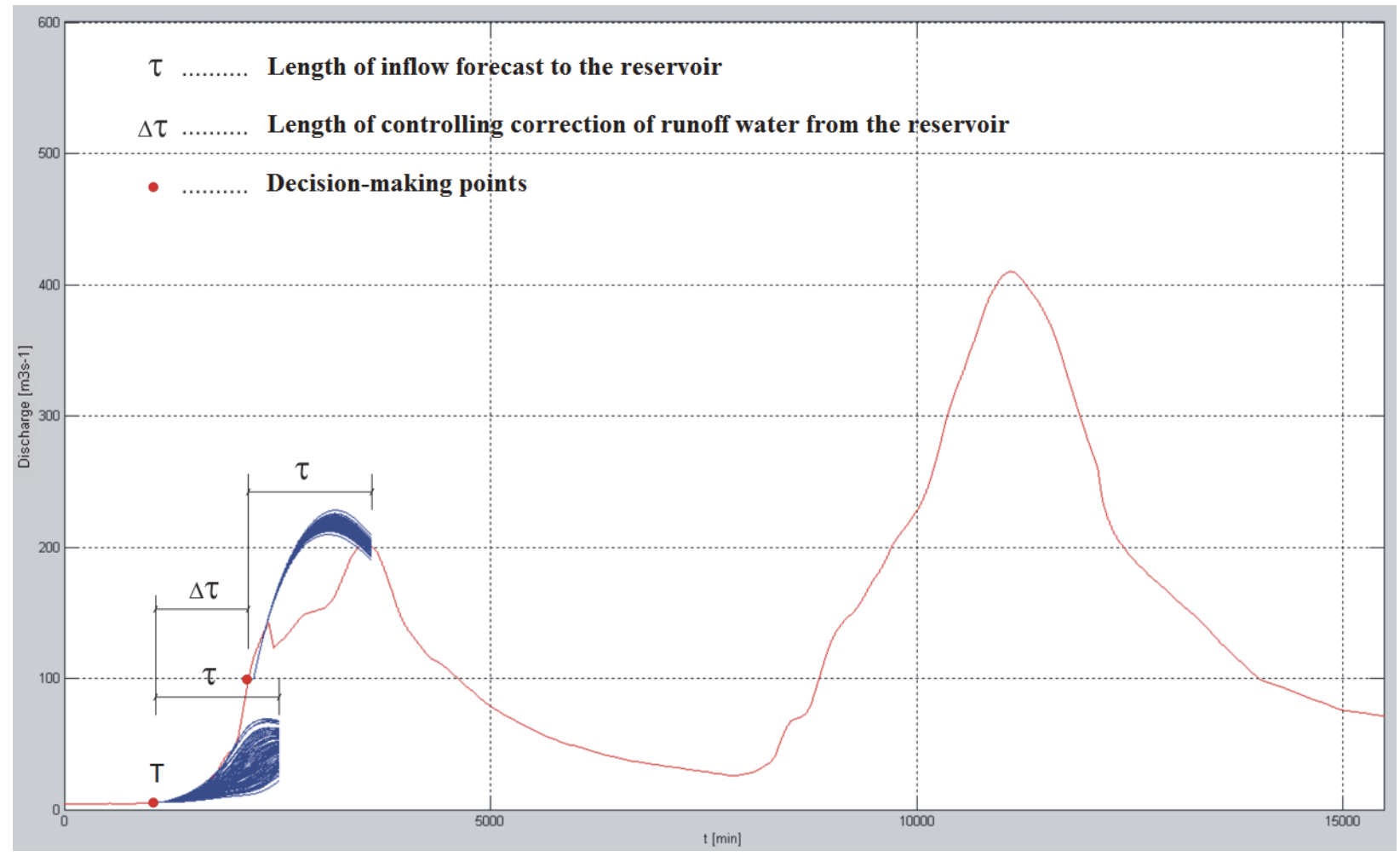

Fig. 2. The principle of the stochastic control of the Vranov reservoir.

The selected waveform of controlled discharge uniquely corresponded to the waveform of the controlling quantity $w(t)$ (controlling discharge), which was subsequently used for the control of the real inflow of water into the reservoir with forecast length $\tau$. The fuzzy regulator was used in order to ensure agreement between the controlling and controlled discharges, with the entire procedure analogically repeated at each subsequent decision-making time point $\mathrm{T}$.

The optimisation task was repeatedly solved for each predicted inflow of water into the reservoir from the inflow stochastic hydrological prediction fans, with the progress of the optimised quantity - the waveform of the controlling quantity $w(t)$ (parameter) - considered for the length of the forecast $\tau$ constant. The optimisation criterion $\pi$ was the value of the culmination discharge of water from the reservoir, which was minimised. For the estimation of optimised parameter values, the uniform comparative method was employed (Dupačová and Lachout, 2006), with the solution obtained via a number of repeated calculations in the chosen variation span. The maximum variation span was limited by the value of maximum flow through the bottom outlet at the maximum retention water level in the reservoir (approx. $245.0 \mathrm{~m}^{3} \mathrm{~s}^{-1}$ ) while the minimum value was considered equal to the minimum residual flow of water under the reservoir (ecological flow $-1.0 \mathrm{~m}^{3} \mathrm{~s}^{-1}$ ).

Non-stationary stochastic boundary conditions for the compiled control algorithm of a water reservoir during a flood situation were stochastically assigned hydrographs of the inflow of water into the reservoir (fan) at the decision-making points. The initial conditions of the solution included the height of the water level in the reservoir and the volume of discharge water from the reservoir at time $t=T$ (opening of the bottom outlets at time $t=T$ ).

A necessary step for the successful construction of the stochastic reservoir control algorithm was the establishment of the selection criteria, on the basis of which the resulting controlled discharge of water from the reservoir at the various decision- making points was set. This selection included the realisation of fulfilling the required properties, i.e. the chosen probability of exceedance $P_{\alpha}=\{5 ; 25 ; 50 ; 75 ; 95\} \%$ at time $t=T+\Delta \tau$.

The results obtained using the stochastic reservoir control method were then added to the resulting waveform of the controlled discharge of water from the reservoir based on the deterministically defined prediction of water inflow into the reservoir. Deterministic prediction data were replaced by measured water inflow into the reservoir, i.e. considering a $100 \%$ match between hydrological predictions and real inflow waveforms. In the presented case the initial volume of water in the reservoir at time $T$ was replaced by the measured volume.

A dynamic continuous process was solved using a discretisation procedure with a computation step of 1.0 minutes.

Analysis of the obtained results is here presented only for the chosen correction of the reservoir control (i.e. $N=26$ ) shown in Figure 3. In the controlling algorithm of water discharge from the reservoir, an analogous procedure is repeatedly applied, as outlined above.

The set of forecast water inflows into the reservoir is, for clarity, presented in the upper part of Figure 3 for a length of forecast $\tau=24$ hours and $N=26$. Forecasted precipitation events have a standard uncertainty $U=\sigma$ of the mean ( $3 \sigma=U_{a}$ with the normal distribution of the forecasted precipitation depending on the actual meteorological prediction). This set of hydrographs is supplemented by a waveform of the corresponding real water inflows (blue curve). The result of the stochastic control for the $95 \%$ probability of exceeding a controlled outflow at time $\mathrm{t}=\Delta \tau$ is shown in the lower part of Figure 3 (red), together with the waveforms of the optimised controlling flows (blue). The green highlighted waveforms of the input (Figure 3 above) and output quantity (Figure 3 bottom) correspond to the selected (95\%) probability of exceeding a controlled discharge at time $t=\Delta \tau$. 


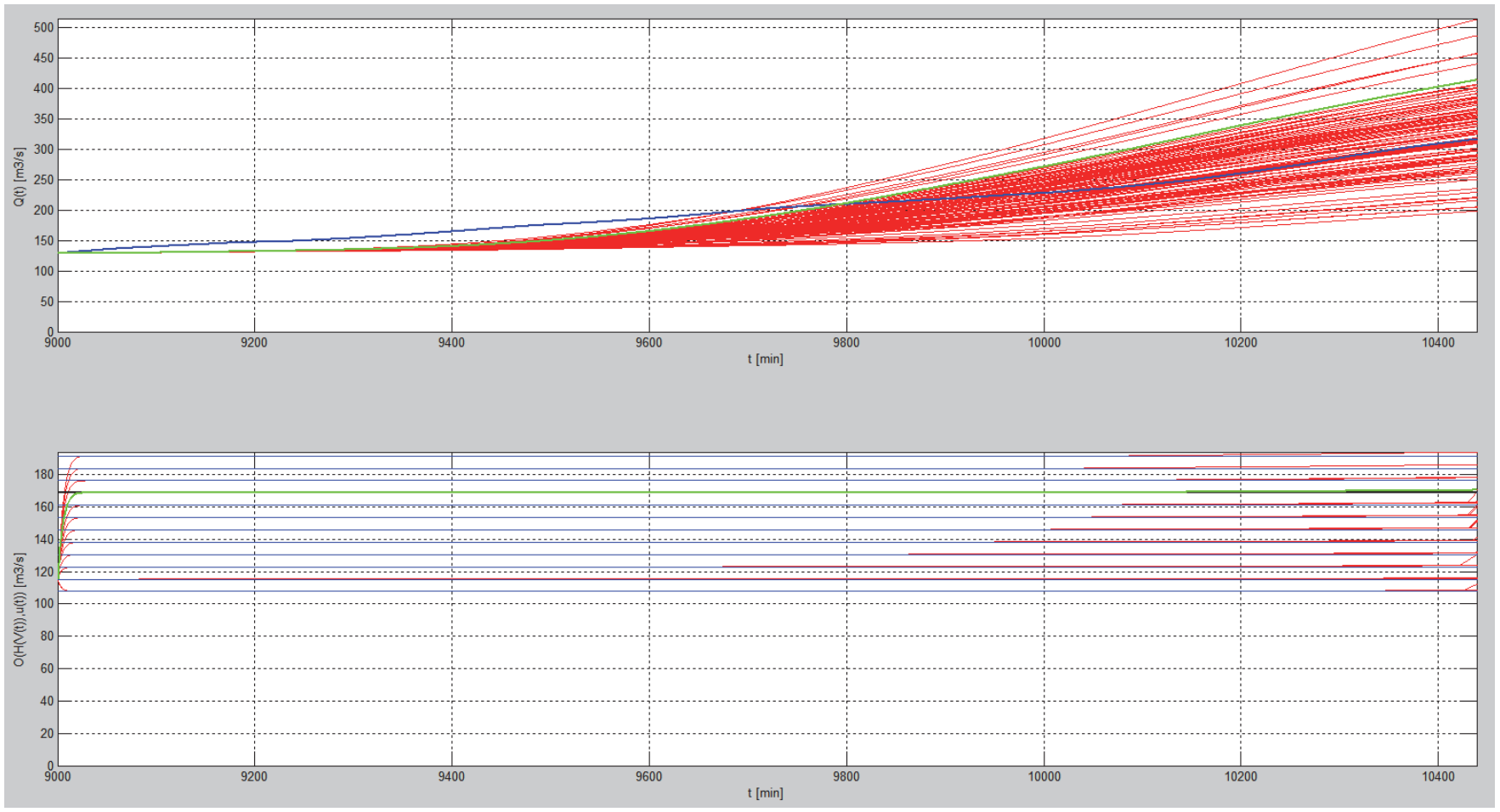

Fig. 3. The matrix of input and output data with length of forecast $\tau=24$ hours and with the number of control corrections $N=26$.
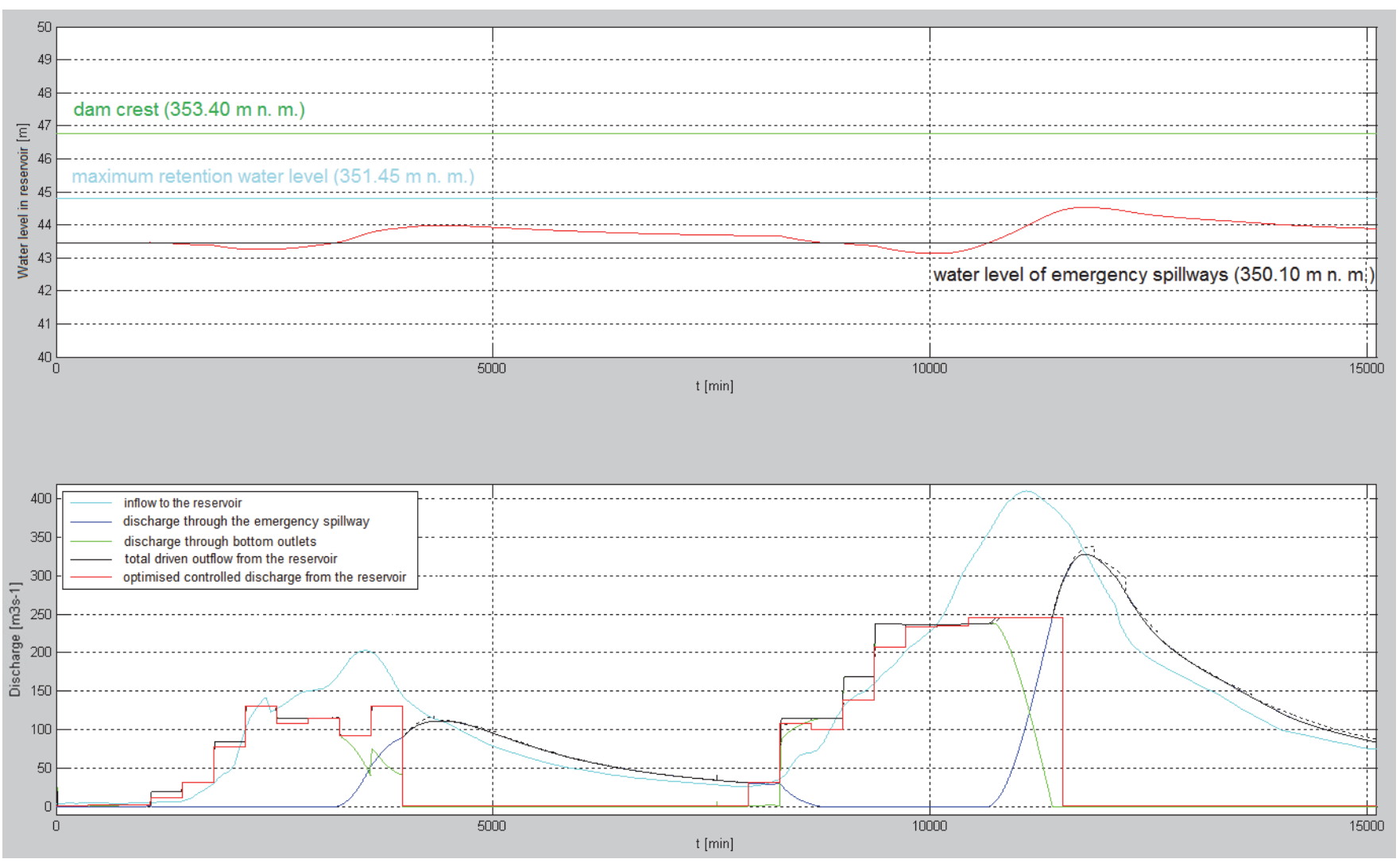

Fig. 4. Flood transformation of the reservoir for $\tau=24$ hours, $\Delta \tau=6$ hours, $P_{\alpha}=95 \%$.

From this Figure, it is clear that the actual value of water inflow into the reservoir at time $t$ is located in the vicinity of the mean value of the stochastic forecasts.

In the upper part of Figure 4, the red line represents the progress of the water level in the reservoir for the simulated period. The lower part of this figure shows the progress of water inflow into the reservoir (light blue), the resulting waveform of optimised controlled discharge from the reservoir $w(t)$ (red), and the resulting total driven outflow from the reservoir $(H(V(t)), u(t))$. The light green line indicates the course of the discharge through bottom outlets (black line), with the 
progress of the discharge through the ungated emergency spillway shown in dark blue.

Figure 5 presents waveforms of the resulting total outflow of water from the reservoir depending on the chosen probability of exceeding the controlled outflow, with that for $P_{\alpha}=5 \%$ shown in red, $P_{\alpha}=25 \%$ in dark blue, $P_{\alpha}=50 \%$ in black, $P_{\alpha}=75 \%$ in purple and $P_{\alpha}=95 \%$ in green. These simulation results for stochastic reservoir control were subsequently supplemented by a waveform of the final controlled discharge from the reservoir for the deterministically specified prediction of water inflow into the reservoir, represented in Figure 5 by the light blue curve (DPP).

The results of the determined culmination of total discharge from the reservoir and the value of the computing time necessary to find a solution are presented in Table 1.

Last but not least, the final tests involved analysing five different methods of choosing the optimal waveform of controlled discharge from the reservoir $w(t)$ at the various decisionmaking points of control, as well as its influence on the obtained simulation results. The employed selection methods are described in detail in the following paragraph.
The results presented in Table 1 are those obtained when applying the previously described method of determining quantity $w(t)$ at the various decision-making points of the procedure used in the selection of the values of controlled discharge from the reservoir at time $t=\Delta \tau$ (signified as simulation number 1 in Table 2). Simulation numbers 2 and 3 involved the determination of the controlled discharge from the reservoir at the decision-making points of the reservoir control procedure, similar to that employed in simulation number 1 , with the difference being that the selection process was applied to the value of the controlled discharge from the reservoir at time $t=\tau$ (simulation number 2), and to the maximum values of controlled discharge for the interval $t=\langle T, T+\tau\rangle$ (simulation number 3). In the final two simulations of stochastic reservoir control, the chosen selection method was applied to the vector of the volumes of controlled discharge from the reservoir for the intervals $t=\langle T, T+\Delta \tau\rangle$ (simulation number 4) and $t=\langle T, T+\tau\rangle$ (simulation number 5). The results of all five simulations are shown in Table 2 below.

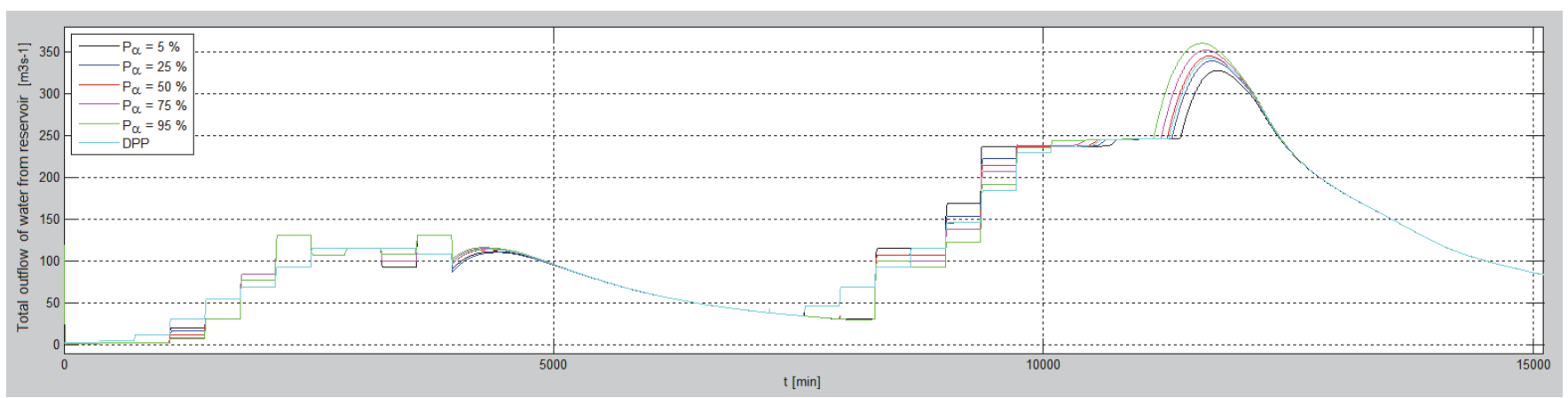

Fig. 5. Variation in total outflow of water from the reservoir with value of $P_{\alpha}$, for $\tau=24$ hours and $\Delta \tau=6$ hours.

Table 1. Culmination of total discharge from the reservoir and the required computing time for length of forecast $\tau=24$ hours and $\Delta \tau=6$ hours.

\begin{tabular}{|c|c|c|c|c|c|c|c|}
\hline \multicolumn{8}{|c|}{ Type of reservoir control } \\
\hline \multicolumn{6}{|c|}{ stochastic } & \multicolumn{2}{|c|}{ deterministic } \\
\hline \multicolumn{5}{|c|}{$\begin{array}{c}\text { Culmination of discharge }\left[\mathrm{m}^{3} \mathrm{~s}^{-1}\right] \text { depending } \\
\text { on the chosen value of } P_{\alpha}[\%]\end{array}$} & \multirow{2}{*}{$\begin{array}{l}\text { Computing time required } \\
\text { for solution } \\
{[\mathrm{hr}]}\end{array}$} & \multirow{2}{*}{$\begin{array}{l}\text { Culmination } \\
\text { of discharge } \\
{\left[\mathrm{m}^{3} \mathrm{~s}^{-1}\right]}\end{array}$} & \multirow{2}{*}{$\begin{array}{c}\text { Computing time required } \\
\text { for solution } \\
{[\mathrm{hr}]}\end{array}$} \\
\hline 5 & 25 & 50 & 75 & 95 & & & \\
\hline 327.80 & 339.13 & 345.04 & 352.07 & 360.26 & 101.3 & 342.3 & 1.8 \\
\hline
\end{tabular}

Table 2. Culmination of total discharge from the reservoir and the value of the required computing time for length of forecast $\tau=24$ hours and $\Delta \tau=6$ hours.

\begin{tabular}{|c|c|c|c|c|c|c|c|c|}
\hline \multirow{4}{*}{$\begin{array}{c}\text { Simulation } \\
\text { no. }\end{array}$} & \multicolumn{8}{|c|}{ Type of reservoir control } \\
\hline & \multicolumn{6}{|c|}{ stochastic } & \multicolumn{2}{|c|}{ deterministic } \\
\hline & \multicolumn{5}{|c|}{$\begin{array}{l}\text { Culmination of discharge }\left[\mathrm{m}^{3} \mathrm{~s}^{-1}\right] \text { depending on the chosen value of } \\
\qquad P_{\alpha}[\%] \text {, obtained by optimisation of control }\end{array}$} & \multirow{2}{*}{$\begin{array}{l}\text { Computing time } \\
\text { required for } \\
\text { solution } \\
{[\mathrm{hr}]}\end{array}$} & \multirow{2}{*}{$\begin{array}{c}\text { Culmination of } \\
\text { discharge } \\
{\left[\mathrm{m}^{3} \mathrm{~s}^{-1}\right]}\end{array}$} & \multirow{2}{*}{$\begin{array}{l}\text { Computing time } \\
\text { required for } \\
\text { solution } \\
{[\mathrm{hr}]}\end{array}$} \\
\hline & 5 & 25 & 50 & 75 & 95 & & & \\
\hline 1 & 327.80 & 339.13 & 345.04 & 352.07 & 360.26 & \multirow{5}{*}{101.3} & \multirow{5}{*}{342.3} & \multirow{5}{*}{1.8} \\
\hline 2 & 327.74 & 339.13 & 345.04 & 352.08 & 360.26 & & & \\
\hline 3 & 327.80 & 339.13 & 345.04 & 352.08 & 360.26 & & & \\
\hline 4 & 327.80 & 339.12 & 345.04 & 352.08 & 360.26 & & & \\
\hline 5 & 327.80 & 339.12 & 345.04 & 352.11 & 360.26 & & & \\
\hline
\end{tabular}




\section{DISCUSSION AND CONCLUSION}

Considering the results presented in Table 1, it follows that the lower the selected probability of exceedance (i.e. the more aggressive the control of the reservoir), the greater the overestimation of real inflow into the reservoir, and thus also the more aggressive the discharging of the retention volume of the controlled reservoir. A qualitatively better transformation effect was achieved using the stochastic method than the deterministic method of reservoir control.

The results of the individual simulations referred to in Table 2 show that the choice between the tested methods used to determine the controlling quantity at the various decisionmaking points does not affect the peak value of controlled water discharge from the reservoir. A more detailed analysis of the partial results for the various decision-making points was then carried out. According to this analysis, at 7 of a total of 39 decision-making points, the deviation between the minimum and maximum volumes of fan-controlled discharge from the reservoir was $5 \%$ to $10 \%$ of the maximum volume. During the simulation of stochastic reservoir control, the water level of the retention volume ranged from 349.80 to $351.40 \mathrm{~m}$ above sealevel, which, based on the flood volume curve, represents 120.6 to 132.3 million $\mathrm{m}^{3}$ of water. This fact, combined with the variation in the volume of predicted inflow into the reservoir during the first flood wave from 0.4 to 16.4 million $\mathrm{m}^{3}$ and during the second flood wave from 2.7 to 32.0 million $\mathrm{m}^{3}$, means that the optimisation method employed does not result in a significantly different mean waveform of optimal reservoir control. The maximum value is achieved during the culmination of inflow when the water level in the reservoir is already in the uncontrollable zone of the reservoir retention space and with regard to the value of the optimisation criterion $\pi$ for the gradual closure of the bottom outlets.

The main disadvantage of the presented stochastic approach to reservoir control appears to be the computing time required to solve the optimisation problem. However, it should be noted that a considerable reduction in computing time can be achieved when writing the stochastic control algorithm in another programming language (e.g. Fortran).

Acknowledgements. This paper was supported by the specific research project FAST-S-15-2694 "Uncertainty propagation in the hydrological and water management applications for mitigation of drought on the open water reservoir". This article is brief summary of the work (Jaroš, 2010).

\section{REFERENCES}

Březková, L., Starý, M., 2013. The stochastic discharge forecast - creation, interpretation and other applications. In: Chavoshian, A., Takeuchi, K. (Eds.): Floods - From Risk to Opportunity. IAHS Publ. 357. International Association of Hydrological Sciences, Centre for Ecology and Hydrology, Wallingford, Oxfordshire, OX10 8BB, UK.

Butcher, W.S., 1971. Stochastic dynamic programming for optimum reservoir operation. JAWRA Journal of the American Water Resources Association, 7, 115-123.

Chandramouli, S., Nanduri, U.V., 2011. Comparison of stochastic and fuzzy dynamic programming models for the operation of a multipurpose reservoir. Water and Environment Journal, 25, 547-554.

Chang, L.-C., Chang, F.-J., 2001. Intelligent control for modeling of real-time reservoir operation. Hydrological Processes, $15,1621-1634$

Chang, Y.-T., Chang, L.-C., Chang, F.-J., 2005. Intelligent control for modeling of real-time reservoir operation, part II: artificial neural network with operating rule curves. Hydrological Processes, 19, 1431-1444.

Chang, L.-C., Chang, F.-J., Hsu, H.-C., 2011. Real-time reservoir operation for flood control using artificial intelligent techniques. International Journal of Nonlinear Sciences and Numerical Simulation, 11, 11, 887-902.

Chaves, P., Tsukatani, T., Kojiri, T., 2004. Operation of storage reservoir for water quality by using optimization and artificial intelligence techniques. Mathematics and Computers in Simulation, 67, 4-5, 419-432.

Drbal, K., 1999. Flood flow operative control by fuzzy regulation in lower part of water management system. $(\mathrm{PhD}$ Thesis). Brno University of Technology. Brno. 96 p.

Dubrovin, T., Jolma, A., Turunen, E., 2002. Fuzzy model for real-time reservoir operation. Journal Water Resources Planning Management, 128, 1, 66-73.

Dupačová, J., Lachout, P., 2006. Introduction to the Optimization. 1st ed. Matfyzpress, Prague, 70 p. ISBN 80-246-0872-3.

Fošumpaur, P., Nacházel, K., Patera, A., 2002. Operative control decision model of flood discharge from reservoir. Journal of Hydrology and Hydromechanics, 50, 1, 29-49.

Jaroš, L., 2010. Use of artificial intelligence methods during operative control of flood flow by reservoir. (PhD Thesis). Brno University of Technology, Brno, $186 \mathrm{p}$.

Nacházel, K., Patera, A., Hejzlar, J., 1999. Control fuzzy model of water quality in reservoir. 1. part - Problem development and methodology of the research. Journal of Hydrology and Hydromechanics, 47, 3, 153-179.

Nacházel, K., Starý, M., Zezulák, J., 2004. Using of Artificial Inteligence Methods in Water Management. 1st ed. Academia, Prague, 319 p. ISBN 80-200-0229-4.

Starý, M., 1990. Reservoirs and Water Management Systems. Brno University of Technology, Faculty of Civil Engineering, Brno, 165 p. ISBN 80-214-0191-5.

Starý, M., 1991-2015. HYDROG. Software for simulation, prediction and operative control of water outflow from catchment area. HySoft, Brno.

Starý, M., 2001. Use of fuzzy regulator during operative control of single reservoir during the flood passage. In: 9th International Poster Day. Institute of Hydrology SAS, Bratislava, $7 \mathrm{p}$.

Starý, M., Doležal, P., 2004. Operative control of outflows from Dyjsko-svratecký system of reservoirs during the flood passage using the Fuzzy regulator. In: WORKSHOP 2004, Prague. Czech Technical University in Prague, Faculty of Civil Engineering, Prague, pp. 54-58.

The Mathworks, 1984-2012. The Language of Technical Computing. Mathworks, Natick, MA.

Received 14 August 2015 Accepted 1 December 2015 